\section{CHEMISTRY}

\section{How does Na Corrode?}

THE effect of liquid sodium on other metals has been a particularly happy hunting ground for chemists ever since it became clear that fast breeder nuclear reactors would make extensive use of sodium in their cooling systems. In the case of the prototype fast reactor (PFR) now being built at Dounreay in the north of Scotland, for example, it is not only the stainless steel pipes and the reactor vessel through which the sodium flows which have to be resistant to corrosion, but also the vital tantalum control rods.

It has been known for some time that oxygen dissolved in the sodium is instrumental in producing the corrosive effects. At $550^{\circ} \mathrm{C}$ in the presence of sodium flowing at $6 \mathrm{~cm} \mathrm{~s}^{-1}-$ a rate comparable with the flow in the core of the PFR - the monthly rate of formation of tantalum corrosion products is 0.9 $\mathrm{mg} \mathrm{cm}{ }^{-2}$ when the oxygen content is 10 p.p.m. and $3.8 \mathrm{mg} \mathrm{cm}^{-2}$ when it is 40 p.p.m. Needless to say, the designers of sodium cooling systems for reactors have long been aware of the problems associated with dissolved oxygen and take careful steps to ensure that it is kept as low as possible.

In the first issue of the new-style Journal of the Chemical Society, Dalton Transactions (No. 1, 13 ; 1972), C. C. Addison, M. G. Barker and D. J. Wood, of the University of Nottingham, report experiments with which they have determined the precise chemical nature of the corrosion products of tantalum and, for good measure, niobium too. Although this is not to say that others, including Barker himself, have not had quite a clear idea of the nature of the tantalum corrosion product - namely mixed oxides of the general form $\mathrm{Na}_{3} \mathrm{Mo}_{4}$ - this is the first time that an absolute identification has been made. One of the problems has been the difficulty of removing sodium from the surface of a tantalum or niobium sample without seriously disturbing the very corrosion products themselves.

Addison and his colleagues carried out an X-ray diffraction analysis of samples of tantalum and niobium, complete with their surface covering of sodium, after they had been immersed in static liquid sodium for several days and at several temperatures. Addison used both wire and plate samples, but in both cases the sodium film had to be protected against the formation by the atmosphere of sodium oxide. Wire samples were protected by a polystyrene film during the process of transfer to the X-ray powder camera, and the plates were examined in the (modified) sample chamber of the powder camera while dry nitrogen was passed through. After the sample had been removed from the liquid, the corrosion product and the sodium layer were removed by scraping and by washing with water so that the lattice parameter of the tantalum or niobium metal near the surface could be accurately assessed.

The changes in the lattice constant of the metal, as compared with that of the pure metal, revealed increases indicative of the formation of a solid metal-oxygen solution in the first instance. At oxygen concentrations in the metal at $600^{\circ} \mathrm{C}$ greater than about 0.57 weight per cent for niobium and 0.21 weight per cent for tantalum, however, the Nottingham group say that $\mathrm{Na}_{3} \mathrm{NbO}_{4}$ and $\mathrm{Na}_{3} \mathrm{TaO}_{4}$ begin to form at the expense of the oxygen in solid solution with the metal.

\section{VIRUSES \\ Finding Virus Proteins}

from our Cell Biology Correspondent

THE chief obstacles to elucidating the replicative cycles of animal viruses stem not so much from the complexity of the virus particles themselves, many of which are less rather than more sophisticated than the bacteriophages, but from the complexity of their hosts, eukaryotic cells. The genomes of the small DNA tumour viruses, polyoma virus and simian virus 40 , for example, have about the same coding capacity as the genome of phage $\phi \times 174$; the viral DNA can code for only about 200,000 daltons of polypeptide which means there are probably fewer than ten virusspecified proteins. Yet identifying any of these proteins, has proved and continues to prove extremely difficult because the synthesis of host cell protein continues unabated, indeed is probably en- hanced, after infection. The problem is picking out a small number of proteins present only in extracts of infected cells from a large number of proteins present in both uninfected and infected cell extracts.

It seems generally agreed that polyoma virus and SV40 particles contain six species of polypeptide. The three minor and basic polypeptide species in polyoma virus particles, and presumably in SV40 particles, are probably derived from cellular histones as Frearson and Crawford (J. Gen. Virol., 14, $141 ; 1972)$ have recently concluded. On the other hand the major capsid protein must presumably be specified by the viral genome and, using double labelling procedures combined with SDS gel electrophoresis, Fischer and Sauer ( $J$. Virol., 9, 1; 1972) have detected the major capsid protein and three other SV40 virion proteins in extracts of infected CV1 cells. These four proteins of the virion normally become detectable after the infection has reached the stage of viral DNA replication and, if DNA replication is blocked with cytosine arabinoside, the synthesis of detectable amounts of these four virion proteins is blocked. In such conditions, however, two virus induced, if not virus coded, proteins can be detected in cell extracts. Whether either of these proteins is SV40 T antigen of induced transplantation antigen remains to be seen, but as Fischer and Sauer modestly comment the identification in extracts of four virion and two non-virion but virus induced proteins is a first step towards the characterization of the proteins essential for the replication of SV40.

Ozer and Tegtmeyer (ibid., 52) have also been investigating the synthesis of the major capsid protein of $S V 40$ in AGMK cells and its assembly into

\title{
Filamentous Fungal Viruses infect Yeasts
}

BACTERIOPHAGES characteristically are extremely host specific. By contrast many viruses of higher plants are able to infect species of more than one genus. Where do the double stranded RNA viruses recently isolated from such filamentous fungi as Aspergillus niger and Penicillium stoloniferum fit into this spectrum; are they as host specific as the bacteriophages or do they have a wide host range? As Lhoas reports in next Wednesday's Nature New Biology (March 22) it seems that in this respect the fungal viruses more closely resemble higher plant viruses than bacteriophages, for they can infect species of more than one genus.

Lhoas succeeded in infecting cells of the yeast Saccharomyces cerevisiae with virus isolated from Aspergillus and Penicillium sp. by exposing cultures of mating yeasts to the virus. From the pattern of appearance of infected colonies of the yeast cells it seems that they are only infected when they are mating, perhaps because mating causes the breakdown of the yeast cell wall. The fact that yeast cells can be infected by these viruses strengthens the case for the conventional classification of yeasts as Ascomycetes.

As Border reports in an accompanying letter, under the electron microscope the development and structure of replicative forms of the virus particles in yeast cells can be seen to be very similar to those that develop in the natural hosts of these viruses, filamentous fungi. In short, these two sets of observations establish beyond doubt that at least some fungal viruses lack strict host specificity. 